\title{
Comparison between emulsified isoflurane and propofol/isoflurane combination on plasma thyroid hormones, insulin, glucose, and glucagon in dogs
}

\author{
Sheng Jiang ${ }^{1}$, Dong Qi Lin ${ }^{1}$, Kui $\mathrm{Hu}^{2}$, De Zhang $\mathrm{Lu}^{3}$, Lin $\mathrm{Li}^{4}$, Feng Ming Guo ${ }^{1}$, \\ Hong Gang Fan $^{1}$ \\ ${ }^{1}$ Northeast Agricultural University, College of Veterinary Medicine, Harbin, Heilongjiang, China \\ ${ }^{2}$ Jilin Agricultural University, College of Veterinary Medicine, Changchun, Jilin, China \\ ${ }^{3}$ Northwest A\&F University, College of Veterinary Medicine, Yangling, Shanxi, China \\ ${ }^{4}$ Shenyang Agricultural University, College of Veterinary Medicine, Shenyang, Liaoning, China
}

Received January 6, 2014

Accepted May 28, 2014

\begin{abstract}
It is important to determine the varying effects of anaesthesia agents on the endocrine function. In this study, the effects of emulsified isoflurane and propofol-isoflurane on the endocrine function were compared in dogs. Sixteen dogs were randomly divided into two groups: one group (G1) of dogs were induced with intravenous $5 \mathrm{mg} / \mathrm{kg}$ propofol and maintained with inhaled $2-2.5 \%$ inspiratory isoflurane in $100 \%$ oxygen; second group $(\mathrm{G} 2)$ of dogs were induced with intravenous $1 \mathrm{ml} / \mathrm{kg}$ emulsified isoflurane and maintained with intravenous $8 \mathrm{ml} / \mathrm{kg} / \mathrm{h}$ emulsified isoflurane. Blood samples to determine the endocrine function were collected prior to induction of anaesthesia and at $15 \mathrm{~min}, 30 \mathrm{~min}, 60 \mathrm{~min}, 2 \mathrm{~h}, 6 \mathrm{~h}$, and $24 \mathrm{~h}$ after drug administration. Serum triiodothyronine and tetraiodothyronine concentrations in G1 increased significantly $(P<0.05)$ at $15 \mathrm{~min}$ and were higher than in G2. Serum insulin at $15 \mathrm{~min}$ and $30 \mathrm{~min}$ were significantly $(P<0.05)$ higher in both G1 and G2. Serum insulin in G1 was higher after anaesthesia than in G2. Serum glucagon decreased at $15 \mathrm{~min}, 30 \mathrm{~min}$, and $60 \mathrm{~min}$, without significant changes $(P>0.05)$. Serum glucose increased at $15 \mathrm{~min}$ and $30 \mathrm{~min}$ after anesthesia, and was significantly higher in G1 than in $\mathrm{G} 2(P<0.05)$ at $60 \mathrm{~min}$. In conclusion, both emulsified isoflurane and propofol-isoflurane anaesthesia affected triiodothyronine, tetraiodothyronine, and insulin in dogs, but emulsified isoflurane anaesthesia had a minimal effect on triiodothyronine and tetraiodothyronine. With its less deleterious effect on the endocrine function, emulsified isoflurane may be more suitable for canine anaesthesia.
\end{abstract}

Anaesthesia, inhalation, intravenous, endocrine, canine

General anaesthesia is commonly used for surgical procedures in small animals. Inhalation is the primary route for maintenance of anaesthesia in dogs and is generally the most preferred approach to optimally control anaesthetic depth and provide anaesthetic support, unlike intravenous (IV) administration of volatile anaesthetics, which carry considerable risk in animals (Kawamoto et al. 1992). Emulsified isoflurane (EI) is an unsaturated lipid emulsion preparation of isoflurane; commercially available preparation is $30 \%$ Intralipid, a sterile, non-pyrogenic fat emulsion prepared for IV administration. Several studies have demonstrated that IV administration of $8 \%$ emulsified isoflurane is safe and effective without adverse effects in rats and dogs (Zhang et al. 2005; Yang et al. 2006; Zhou et al. 2006). An ideal anaesthetic should be predictable, maintain a sufficient duration, provide adequate postoperative analgesia, and importantly, should not interfere with the endocrine system. Unfortunately, anaesthesia has previously been shown to provoke changes in the immune and endocrine function (Ma and Wang 2006). In healthy animals, insulin, enhancing glucose disposal, storage and oxidation, is regulated by serum glucose concentration, controls the metabolites required in the muscle, and has an important role in maintaining glucose homeostasis with glucagon (Máčajová et al. 2003; Kolevská et al. 2004). Proper thyroid function is essential for maintaining cardiovascular integrity

Address for correspondence:

Hong-Gang Fan, PhD

College of Veterinary Medicine

Northeast Agricultural University

Harbin 150030, Heilongjiang Province, China 
during normal and stressful situations. However, there are no known studies evaluating the effects of EI and propofol-isoflurane anaesthetics on the endocrine function in dogs.

The present study thus evaluates and compares the effects of emulsified isoflurane and propofol-isoflurane on triiodothyronine $\left(\mathrm{T}_{3}\right)$, tetraiodothyronine $\left(\mathrm{T}_{4}\right)$, insulin (INS), glucagon (GN), and glucose (Glu) before, during, and after anaesthesia in dogs.

\section{Methods and Materials}

The study protocol was approved by the Northeast Agricultural University Committee on Animal Care and Use. In total, 16 healthy adult dogs (6 females and 10 males, aged 2-6 years, weighing $4.5-5.5 \mathrm{~kg}$ ) were selected, and the subjects were housed individually, fed dry kibble twice daily, and water ad libitum. The dogs were judged healthy based on routine physical examination, complete blood count, biochemical profile, and electrocardiogram.

Emulsified isoflurane was prepared according to the procedures described in the published literature (Yang et al. 2006). In summary, $0.8 \mathrm{ml}$ liquid isoflurane (Forane ${ }^{\circledR}$, Abbott Laboratories Trading (Shanghai) Co., Ltd., Shanghai, China) and $9.2 \mathrm{ml} \mathrm{30 \%} \mathrm{Intralipid} \mathrm{(Libangyingte}{ }^{\circledR}$, Xi'an LiBang Pharmaceutical Co., Ltd., Xi'an, China) were put into a $10 \mathrm{ml}$ glass ampoule, and the ampoule was preserved with seal by an alcohol blowtorch. The ampoule was vigorously shaken by a vibrator for $15 \mathrm{~min}$ to dissolve isoflurane into the lipid emulsion. There were no changes in the isoflurane concentration, and no lipid droplets were found during 6 months of storage at room temperature.

The dogs were randomly assigned to two groups $(n=8)$ receiving different anaesthetic protocols as follows: Group 1 (G1) was administered $0.02 \mathrm{mg} / \mathrm{kg}$ intramuscular (IM) atropine (Southwest Pharmaceutical Co., Ltd., Chongqing, China) followed by $5 \mathrm{mg} / \mathrm{kg}$ propofol (Force MengXin ${ }^{\circledR}$, Xi'an LiBang Pharmaceutical Co., Ltd., Xi'an, China) IV 15 min later; then, $2-2.5 \%$ of inspiratory isoflurane in a $100 \%$ oxygen circuit was administered by inhalation with endotracheal intubation. Group 2 (G2) was administered $0.02 \mathrm{mg} / \mathrm{kg}$ i.m. atropine followed by $1 \mathrm{ml} / \mathrm{kg}$ emulsified isoflurane IV $15 \mathrm{~min}$ later, and finally, $8 \mathrm{ml} / \mathrm{kg} / \mathrm{h}$ emulsified isoflurane IV.

Prior to induction, food was withheld for $12 \mathrm{~h}$ and water for $2 \mathrm{~h}$ before anaesthesia. Two hours before the experiment, the animals were taken to the operating room by the feeders to acclimatize to the operating room and staff to minimize stress and the need for physical restraint. An intravenous catheter was placed into either the left or right cephalic vein, flushed with heparinized saline, and secured. The heart rate (HR) and blood pressure were recorded during the anaesthetic period using a non-invasive patient monitor (Datex-OhmedaS/5; Datex-Ohmeda Division Instrumentarium Corp. Helsinki, Finland). For the measurement of the mean arterial pressure (MAP) and HR, an adjustable blood pressure cuff was positioned around the left antebrachium of each dog. HR was determined by placing the ECG electrodes from the monitor, according to the instruction.

Blood ( $2 \mathrm{ml}$ ) containing no anticoagulant agent was collected by venipuncture from the right forelimb cephalic vein into vacuum blood collection tubes (Chengdu Rich Science Industry Co., Ltd., Chengdu, China) with no additive, prior to pre-anaesthetic drug administration and served as the baseline data ( $0 \mathrm{~h}$; control). Immediately after blood sampling, atropine was administered to the subjects, followed by anaesthetic induction $15 \mathrm{~min}$ later, as described for each group. Anaesthetic induction was defined as complete when righting reflexes were lost, and this time interval, as well as certain subjective criteria, was recorded for each experimental group. After induction, general anaesthesia was maintained for $1 \mathrm{~h}$ using either inhaled isoflurane (G1) or emulsified isoflurane (G2). Venous blood samples $(2 \mathrm{ml})$ were collected at $15 \mathrm{~min}, 30 \mathrm{~min}, 1 \mathrm{~h}, 2 \mathrm{~h}, 6 \mathrm{~h}, 12 \mathrm{~h}$, and $24 \mathrm{~h}$ during and following anaesthesia. After collection blood samples were placed at room temperature for $15 \mathrm{~min}$, and then centrifuged at $1500 \times \mathrm{g}$ for $10 \mathrm{~min}$; serum was stored at $-80^{\circ} \mathrm{C}$ as soon as possible. Serum $\mathrm{T}_{3}$ and $\mathrm{T}_{4}$ concentrations were measured by radioimmunoassay (RIA) using commercial kits (ICN Pharmaceuticals, Inc, Costa Mesa, CA), and INS, GN, and Glu were measured by RIA using commercial kits (Linco Research, St. Charles, MO) according to the manufacturer's instructions.

All data are expressed as mean \pm standard deviation (SD). One-way analysis of variance (ANOVA) for repeated measures followed by the least significant difference test was performed on data within each group. Significance was defined as $P<0.05$. All statistical analyses were performed using SPSS v13.0 for Windows (SPSS Inc., Chicago, IL, USA).

\section{Results}

No complications or significant events were observed during anaesthesia and recovery. Heart rates (HR) are shown in Fig. 1A. Baseline HR did not significantly differ between the treatment groups; HR in G2 did increase at $15 \mathrm{~min}$, but this change was not significant and returned to baseline. HR increased in G1 at $15 \min (P<0.05)$ and then returned to baseline values from $30 \mathrm{~min}$ to $24 \mathrm{~h}$. Mean arterial pressure (MAP) is presented in Fig. 1B. Baseline MAP were not significantly different between the treatment groups, but MAP decreased significantly $(P<0.05)$ in both treatment groups at $30 \mathrm{~min}$ and $1 \mathrm{~h}$ after drug 

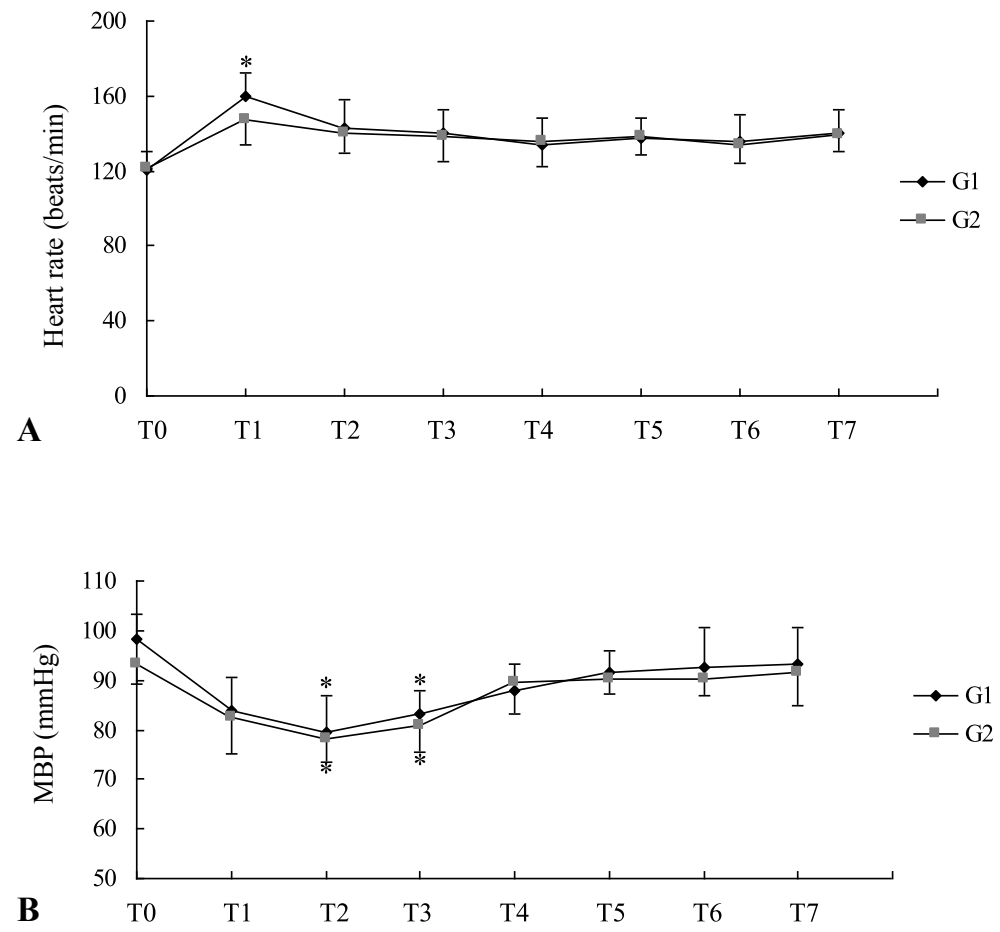

Fig. 1. Mean $\pm \mathrm{SD}$ of (A) heart rate and (B) blood pressure (MAP) following administration of propofol-isoflurane (Group 1, G1) or emulsified isoflurane (Group 2, G2). Values were recorded before drug administration (T0), and at $15 \mathrm{~min}$ (T1), $30 \mathrm{~min}$ (T2), $1 \mathrm{~h}$ (T3), $2 \mathrm{~h} \mathrm{(T4),} 6 \mathrm{~h}$ (T5), $12 \mathrm{~h}$ (T6), and $24 \mathrm{~h}$ (T7) after anaesthesia. * Significance $(P<0.05)$ within each group and \& significance $(P<0.05)$ between the treatment groups.

administration, and then increased and remained at baseline for the rest of the experimental period.

Concentrations of $\mathrm{T}_{3}$ (Fig. 2A) and $\mathrm{T}_{4}$ (Fig. 2B) in $\mathrm{G} 1$ increased significantly $(P<0.05)$ at $15 \mathrm{~min}$, then decreased back to baseline values from $30 \mathrm{~min}$ to $24 \mathrm{~h}$ after drug administration; however, in G2, while there was a steady increase in $T_{3}$ and $T_{4}$, the changes were not significant. Serum INS in G1 (Fig. 2C) increased significantly $(P<0.05)$ at $15 \mathrm{~min}$ and $30 \mathrm{~min}$, then decreased back to baseline from $1 \mathrm{~h}$ to $24 \mathrm{~h}$. In G2, serum INS rose steadily after EI treatment, but this change was not significant. As shown in Fig. 2D, baseline GN was not significantly different between the treatment groups. In both groups, GN decreased at $15 \mathrm{~min}, 30 \mathrm{~min}$, and $60 \mathrm{~min}$, and then returned to baseline for the remainder of the experimental period, but these changes were not significant. In both groups, serum Glu increased at $15 \mathrm{~min}$ and $30 \mathrm{~min}$, and returned to baseline for the remainder of the period, with no significant difference noted (Fig. 3). Serum Glu in G1 was significantly higher $(P<0.05)$ than in the $\mathrm{G} 2$ group at $60 \mathrm{~min}$.

\section{Discussion}

Mean arterial pressure decreased after the administration of anaesthetic in both groups at $15 \mathrm{~min}$, and substantially decreased at $30 \mathrm{~min}$ and $60 \mathrm{~min}$ before returning to baseline. 
A
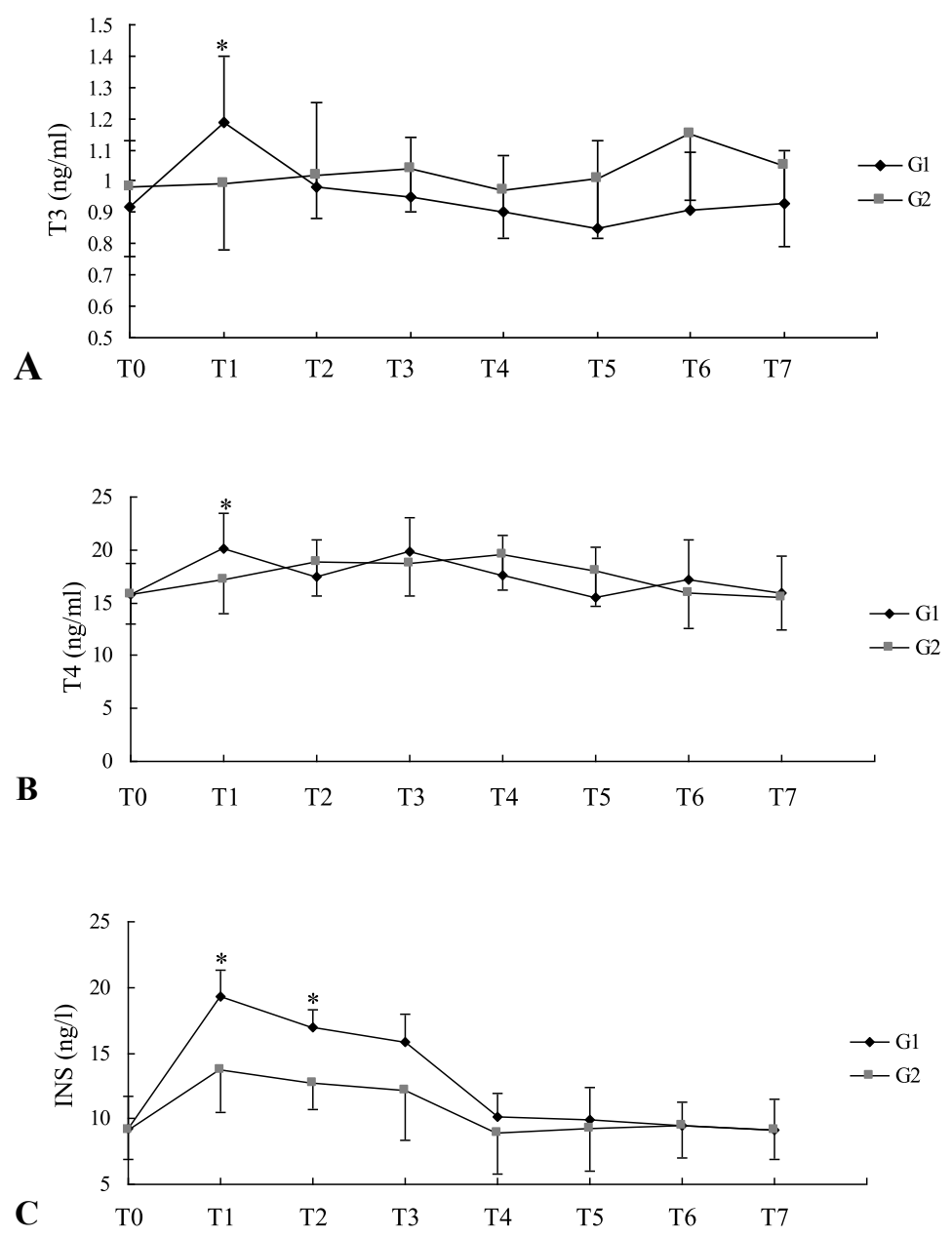

D

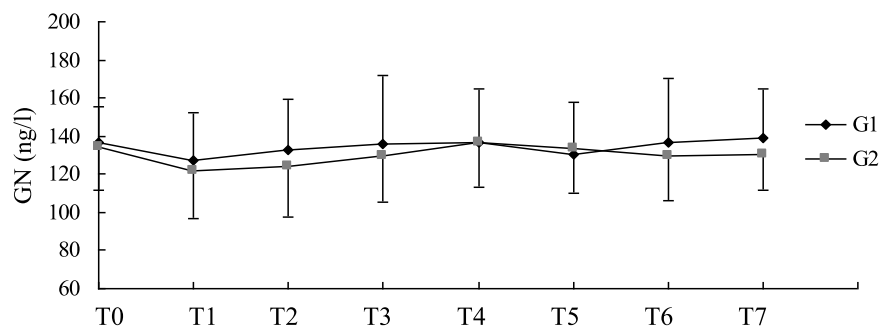

Fig. 2. Mean $\pm \mathrm{SD}$ serum (A) triiodothyronine $\left(\mathrm{T}_{3}\right)$, (B) tetraiodothyronine $\left(\mathrm{T}_{4}\right),(\mathrm{C})$ insulin (INS), and (D) glucagon (GN) following administration of propofol-isoflurane (Group 1, G1) or emulsified isoflurane (Group 2, G2). Values were recorded before drug administration (T0), and at $15 \mathrm{~min}$ (T1), $30 \mathrm{~min}$ (T2), $1 \mathrm{~h}$ (T3), $2 \mathrm{~h}$ (T4), $6 \mathrm{~h}$ (T5), $12 \mathrm{~h}$ (T6), and $24 \mathrm{~h}$ (T7) after anaesthesia. * Significance $(P<0.05)$ within each group and \& significance $(P<0.05)$ between the treatment groups. 


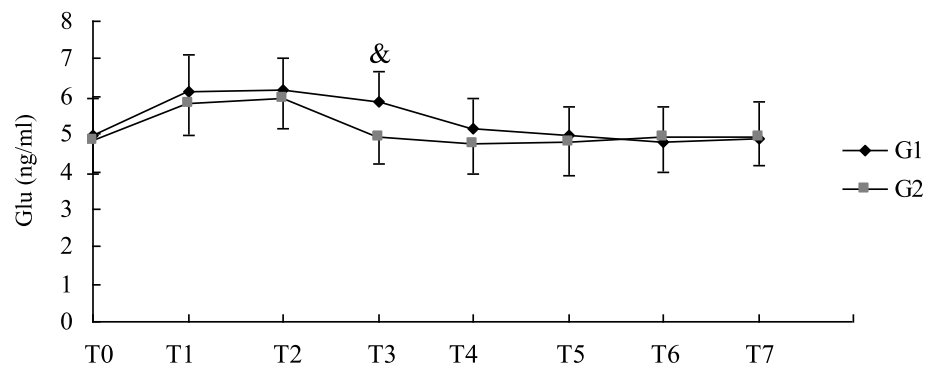

Fig. 3. Mean \pm SD serum glucose (Glu) following administration of propofol-isoflurane (Group 1, G1) or emulsified isoflurane (Group 2, G2). Values were recorded before drug administration (T0), and at 15 min (T1), $30 \mathrm{~min}$ (T2), $1 \mathrm{~h}$ (T3), $2 \mathrm{~h}$ (T4), $6 \mathrm{~h}$ (T5), 12 h (T6), and $24 \mathrm{~h}$ (T7) after anesthesia. * Significance $(P<0.05)$ within each group and $\&$ significance $(P<0.05)$ between the treatment groups.

This change may be caused by the direct effects of isoflurane on the sympathetic nervous system, which causes decreased blood pressure (Eger 1984). In addition, the heart rate increased immediately after anaesthetic administration in both groups. The blood pressure decrease may have also triggered a heart rate increase through the decompression reflex. Furthermore, atropine also could induce the increase of heart rate, and isoflurane may decrease the vagal tone on the heart, which would also increase the heart rate (Picker et al. 2001).

$\mathrm{T}_{3}$, insulin, and glucagon promote the cellular metabolism of sugar, fat, and protein, and accelerate cell growth. Anaesthetics influence these endocrine hormones in numerous ways, and these endocrine changes may influence postoperative wound healing, recovery, and even the immune function. A prior study demonstrated that isoflurane reduced the Glu metabolism, induced hyperglycaemia, and inhibited pancreatic insulin release (Zuurbier et al. 2008). In another study, enflurane anaesthesia reportedly inhibited pancreatic insulin release and elevated blood glucose (Ewart et al. 1981). Our study showed similar effects on serum insulin and glucose in dogs anaesthetized with either propofol-isoflurane or emulsified isoflurane. Ether anaesthesia reportedly induces decreased serum $\mathrm{T}_{3}$ and $\mathrm{T}_{4}$ over time (Huang et al. 1991). In contrast, serum $\mathrm{T}_{3}$ and $\mathrm{T}_{4}$ actually increased intra-operatively and immediately postoperatively in humans, which was attributed not to surgical trauma but to inhalational anaesthetics (Chikenji et al. 1990); our data support these latter reports. It has also been reported that enflurane anaesthesia causes the most significant increase in free and total thyroxine in a short period (Wang and Chen 1997).

In conclusion, both EI and propofol-isoflurane anaesthesia affected $\mathrm{T}_{3}, \mathrm{~T}_{4}$, and INS in dogs, but EI anaesthesia had a minimal effect on $\mathrm{T}_{3}$ and $\mathrm{T}_{4}$. With its less deleterious effect on the endocrine function, emulsified isoflurane may be more suitable for canine anaesthesia.

\section{Acknowledgements}

This study was supported by the National Natural Science Foundation of China (Grant no.: 31001092; 31272617) and the Open Projects of Key Laboratory of Feed Science, College of Heilongjiang Province (Grant no.: yy-2012-11).

\section{References}

Chikenji T, Mizutani M, Kitsukawa Y 1990: Anaesthesia, not surgical stress, induces increases in serum concentrations of reverse triiodothyronine and thyroxine during surgery. Exp Clin Endocr Diab 95: 217-223

Eger EI 1984: The pharmacology of isoflurane. Br J Anaesth 56: 71-99 
Ewart RBL, Rusy BF, Bradford MW 1981: Effects of enflurane on release of insulin by pancreatic islets in vitro. Anesth Analg 60: 878-884

Huang YM, Chen XH, Zhang R 1991: Influence of low power laser on the thyroid hormone secretion of rat. Mod Med J 19: 5-6

Kawamoto M, Suzuki N, Takasaki M 1992: Acute pulmonary edema after intravenous liquid halothane in dogs. Anesth Analg 74: 747-752

Kolevská J, Husník R, Brunclík V, Mandys V, Vernerová Z, Schánilec P, Bartosová L, Svoboda M 2004: A case of canine insulinoma. Acta Vet Brno 73: 353-358

Máčajová M, Lamosová D, Zeman M 2003: Physiological effects of leptin, insulin and triamcinolon on adult male Japanese quail. Acta Vet Brno 72: 515-522

Ma HZ, Wang JK 2006: Insulin resistance syndrome and anesthesia. Int J Ane Res 27: 47-49

Picker O, Scheeren TW, Arndt JO 2001: Inhalation anesthetics increase heart rate by decreasing cardiac vagal activity in dogs. Br J Anaesth 87: 748-754

Wang M, Chen SY 1997: Effects of anesthesia on delivery and metabolism of thyroid hormones. Int J Anesth Res 18: 319

Yang XL, Ma HX, Yang ZB, Liu AJ, Luo NF, Zhang WS, Wang L, Jiang XH, Li J, Liu J 2006: Comparison of minimum alveolar concentration between intravenous isoflurane lipid emulsion and inhaled isoflurane in dogs. Anesthesiology 104: 482-487

Zhang WS, Ma HX, Yang XL, Luo NF, Liu J 2005: Anesthetic potency and safety of isoflurane injection in rats and dogs. Anesthesiology 103: A745

Zhou JX, Luo NF, Liang XM, Liu J 2006: The efficacy and safety of intravenous emulsified isoflurane in rats. Anesth Analg 102: 129-134

Zuurbier CJ, Keijzers PJM, Koeman A, Van Wezel HB, Hollmann MW 2008: Anesthesia's effects on plasma glucose and insulin and cardiac hexokinase at similar hemodynamics and without major surgical stress in fed rats. Anesth Analg 106: 135-142 